\title{
VIBROMETER TO MEASURE OCCLUSION FORCE ON TEETH USING IMAGE PROCESSING
}

\author{
SukeshiniTamgade ${ }^{1}$, Vidhi M. Chakradhare ${ }^{2}$, Vandana K. Sarve ${ }^{3}$, Snehal R.Choudhari ${ }^{4}$, \\ MonaliG.Wankhade ${ }^{5}$ \\ ${ }^{I}$ Professor, Electronics, DBACER, RTMNU, Nagpur, Maharashtra \\ ${ }^{2}$ Student, Electronics, DBACER, RTMNU, Nagpur, Maharashtra \\ ${ }^{3}$ Student, Electronics, DBACER, RTMNU, Nagpur, Maharashtra \\ ${ }^{4}$ Student, Electronics, DBACER, RTMNU, Nagpur, Maharashtra \\ ${ }^{5}$ Student, Electronics, DBACER, RTMNU, Nagpur, Maharashtra
}

\begin{abstract}
It is seen that there is decrease in the density of jawbone and the bone around the teeth over the years of person. As a result it creates the occlusal force on teeth. When the force exceeds the adaptive capacity of the tissues which gets injured that resultant injury is termed as trauma from occlusion. There is no such device to check the occlusal force on teeth. Therefore doctor measure force with the help of index finger but occlusive force cannot be measured accurately and satisfactorily. Due to this we are designing a device known as Vibrometer to detect the occlusal force on teeth. The device consists of a probe through which the waveform will be drawn, a drum will be used to rotate the paper, and a stand will be used to stable the head and in MATLAB the waveform will be analyzed.
\end{abstract}

Keywords: vibrometer, image processing, Pattern Recognition, MATLAB software.

\section{INTRODUCTION}

\subsection{Occlusal Force}

The force exerted on opposing teeth when the jaws are closed or tightened is called as an occlusal force. It is the result of muscular force applied on opposing teeth.

After many efforts have been made over the years to calculate the occlusal force, till now to measure the occlusal force the treatment was done by analyasingthe frequency of vibration in teeth by keeping the doctor's index finger on the gums of the patient and sense the vibration manually. But it didn't give the satisfactory result.

In winter our hands get cold and losses its sensation. In this case when doctor checks the patients by keeping his index finger on the gum, the actual vibration may not feel. In this case doctor analyses only on the guessing and gives the medicine. From this doctor do not get the result accurately and satisfactorily. If the occlusal force on teeth is high it also leads to injury inside the mouth.
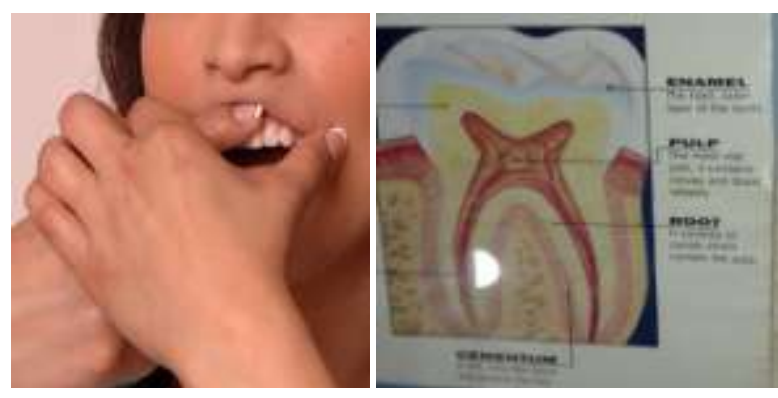

There were many ideas developed to cure this problem such as miniature metallic bite forks, electromyography activity of the master, even sound transmission on the forehead and chin were used to estimate occlusal force.

Due to this patient feel discomfort during the measurement process and the measurement error was quite sever. Therefore the proper treatmentisverymuch necessary.

\section{VIBROMETER}

\subsection{Device Description}

Vibrometer is the device to measure the occlusal force on the teeth which is occurred due to the force exerted on teeth when the jaws are closed or tightened. The device consists of a plastic probe, a paper rotating drum and a stand to stable the patients head.

Vibration sensing probe is made up of plastic. The probe is disposable. As this device is flexible, therefore can be fitted to any jaw. At the bottom of the probe marker is attached. Vibration sensing probe is able to analyze the overall magnitude of vibration in teeth. The parameter can be obtained by the response wave of vibrating tooth.

This vibration system is suitable for medical application, due to its flexibility, softness and there are no worries of injuries inside the mouth and give the accurate measurement. There will be no pain during this check up. 


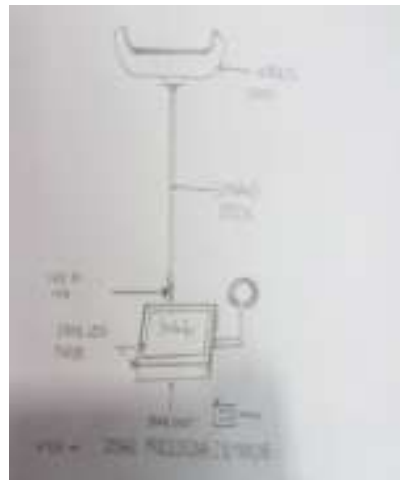

Fig.1: Probe of Vibrometer

The strip of Vibrometer is made up of plastic material. It can be fitted as per the curve of the jaw of the patient. The probe is up to $6-8 \mathrm{~cm}$ in height.

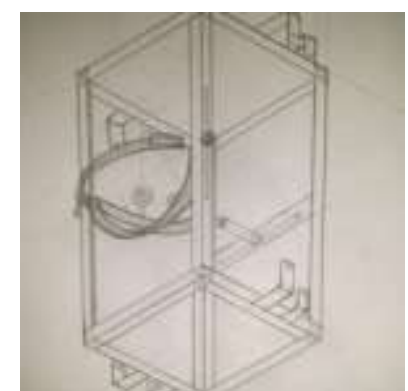

Fig.2: Stand of Vibrometer

\subsection{Working}

The stand has a small drum on which paper is rolled. Height of stand is adjustable. A $12 \mathrm{~V}$ small motor is connected to the drum which rotates the paper and the marker which is kept on the drum with the help of that marker the magnitude of frequency can be drawn on piece of paper which is placed on the drum.

The frequency response characteristics are observed through image processing. The image of the magnitude of frequency will be taken observing by using image processing software.

\subsection{Advantages}

1. As the material used is oflow cost and easily available so this device is easy to use

2. Hygienically is very effective.

3. It is easy to use and throw.

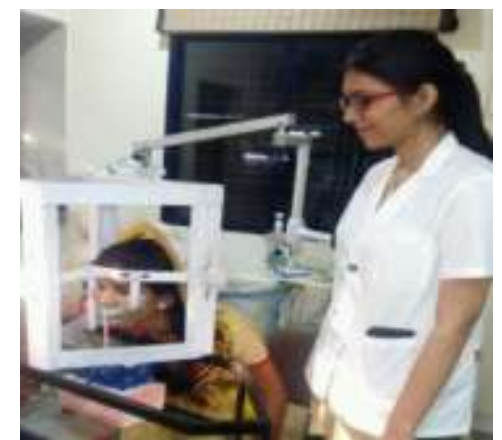

Fig.3: Implementation of Vibrometer

\section{SOFTWARE USED}

The software used is MATLAB. MATLAB is a highperformance language for technical computing. It integrates computation, visualization, and programming in an easy-touse environment where problems and solutions are expressed in familiar mathematical notation. Typical uses include: Math and computation.

Image processing is a method to convert an image into digital form and perform some operations on it, in order to get an enhanced image or to extract some useful information from it. It is a type of signal dispensation in which input is image, like video frame or photograph and output may be image or characteristics associated with that image. Usually Image Processing system includes treating images as two dimensional signals while applying already set signal processing methods to them.

The purpose of image processing is divided into 3 groups. They are:

1. Croping - Crop the image.

2. Measurement of pattern - Measures various objects in an image.

3. Image Recognition - Distinguish the objects in an image

With the help of device we will get the one image in the form of waveform then this waveform will be analyzed the MATLAB software with the help ofPattern Recognition techniqueand as per the analysis the doctor will give the proper treatment.

\section{CONCLUSION}

In this paper, new device known as Vibrometer is proposed.

1. This study was performed on the experimental basis, it is seen that it is medically applicable.

2. The biological response and stress distribution can be assessed.

3. Due to further surveys, investigation by using this vibration sensing probe in humans is needed.

4. With the help of device we will measure occlusal force.

\section{REFERENCES}

[1] MineichiKudo, Jack Sklansky (2000). "Comparison of algorithms that select features for pattern classifiers". Pattern Recognition33 (1): 25-41.

[2] IOSR Journal of VLSI and Signal Processing (IOSRJVSP) "Vibrometer to detect the occlusal force on teeth using Image Processing". Volume 5, Issue 4, Ver. II (Jul-Aug. 2015), PP 14-15 e-ISSN:2319-4200, p-ISSN No. :2319-4197.

[3] Carvalko, J.R., Preston K.(1972). "On Determining Optimum Simple Golay Marking Transforms for Binary Image Processing". IEEE Transactions on Computers 21:1430-33.

[4] Gilat, Amos (2004). "MATLAB: An Introduction with Applications $2^{\text {nd }}$ Edition". John Wiley \&Sons.ISBN 978-0-471-69420-5. 